\title{
Comparison of Silane Heat Treatment by Laser and Various Surface Treatments on Microtensile Bond Strength of Composite Resin/Lithium Disilicate
}

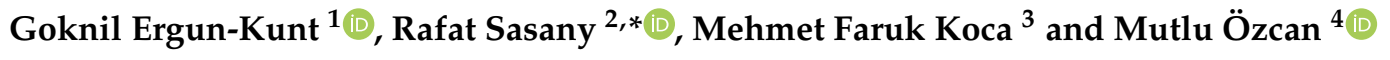 \\ 1 Department of Prosthodontics, Faculty of Dentistry, University of Ondokuz Mays, Samsun 55420, Turkey; \\ gergun@omu.edu.tr \\ 2 Independent Researcher, Samsun 55020, Turkey \\ 3 Department of Periodontology, Faculty of Dentistry, University of Ondokuz May1s, Samsun 55420, Turkey; \\ mfarukkoca@yahoo.com \\ 4 Center of Dental Medicine, Division of Dental Biomaterials, Clinic for Reconstructive Dentistry, \\ University of Zurich, 8032 Zurich, Switzerland; mutluozcan@hotmail.com \\ * Correspondence: sasanyr@gmail.com
}

check for updates

Citation: Ergun-Kunt, G.; Sasany, R.; Koca, M.F.; Özcan, M. Comparison of Silane Heat Treatment by Laser and Various Surface Treatments on Microtensile Bond Strength of Composite Resin/Lithium Disilicate. Materials 2021, 14, 7808. https:// doi.org/10.3390/ma14247808

Academic Editors: Francesco Baino and Paolo Cappare

Received: 24 October 2021

Accepted: 12 December 2021

Published: 16 December 2021

Publisher's Note: MDPI stays neutral with regard to jurisdictional claims in published maps and institutional affiliations.

Copyright: (c) 2021 by the authors. Licensee MDPI, Basel, Switzerland. This article is an open access article distributed under the terms and conditions of the Creative Commons Attribution (CC BY) license (https:/ / creativecommons.org/licenses/by/ $4.0 /)$.

\begin{abstract}
In the current study, we evaluated the effects of heat treatment (by Er:YAG or furnace) and various surface treatments on the microtensile bond strength ( $\mu$ TBS) of silanized lithium disilicate ceramic. Seventy lithium disilicate (IPS e. max Press; Ivoclar Vivadent) and composite resin (Tetric N-Ceram; Ivoclar Vivadent) blocks were made and distributed into seven groups $(n=10)$ at random: S: silanization alone; ALS: airborne particle abrasion (APA) and silanization; SC: APA modified with silica and silanization; SHT1: silanization and heat treatment by Er:YAG; SHT2: silanization and heat treatment performed in the furnace $\left(100{ }^{\circ} \mathrm{C}, 1 \mathrm{~min}\right)$; HF: etching with HF; and HFS: etching with $\mathrm{HF}$ and silanization. Every ceramic specimen was cemented to a composite resin block after surface treatment. Cemented specimens were embedded into acrylic resin and were tested with the $\mu$ TBS test. Data were analyzed using one-way ANOVA and Tamhane T2 tests $(\alpha=0.05)$. The SHT1 group had the highest bond of strength compared to the other groups $(27.46 \mathrm{MPa})$. The ALS group had the lowest strength of the groups (15.56 MPa). Between SHT2 and HFS $(p=1)$, the comparison of the mean $\mu$ TBS values showed no significant differences. It was concluded that silane heat treatment increased the resin composite-ceramic bond strength; however, within the terms of $\mu$ TBS, the Er:YAG laser treatment was more successful than other surface treatment applications.
\end{abstract}

Keywords: adhesion; bond strength; ceramic; Er:YAG laser; heat treatment; silane

\section{Introduction}

Aesthetics is one of the most critical characteristics in dentistry that has significantly increased the usage of all-ceramic systems [1-5]. All-ceramic materials for the manufacture of fixed dental prostheses play an essential role in rehabilitation. Lithium disilicate glass-ceramics are an alternative to traditional materials and have excellent aesthetic and mechanical properties [6-11]. Resin composite is widely used in definitive prostheses and temporary veneers due to its stability, excellent mechanical properties, and desirable aesthetics. Temporary veneers are also fundamental materials used in prosthetic rehabilitation and have essential biological, aesthetic, and practical functions [12,13]. Providing a reliable, permanent bond between the all-ceramic restoration and resin composite is essential for long-term clinical success. In addition, it is essential in terms of providing a balanced distribution of occlusal contacts $[14,15]$. The composite-ceramic bond is dependent on the adhesion of the composite resins to the ceramic surface treatment used, and these current processes are based on micromechanical and chemical bonding [16,17]. The ceramic surfaces are prepared in a variety of ways [18], such as hydrofluoric acid etching, (HF) $[16,17,19-27]$ silica coating [19], abrasion by airborne aluminum oxide particles [28], 
and laser irradiation [29]. These methods are used to increase surface roughness and bond strength. Air abrasion may improve ceramic surface roughness and wettability; however, it induces microcracks in the structure and leads to new fractures in the long term [28]. In addition, the intraoral method may be limited due to the unfavorable operating circumstances associated with alumina particles [28]. The chemical bond between ceramic and composite resin is mainly caused by silane coupling agents; by forming a siloxane bond in response to an increase in the surface energy of the ceramics and the wettability of the cement, silane coupling agents establish adhesion between the inorganic phase of the ceramic and the organic phase of the bonding agent applied to the ceramic surface, resulting in microscopic interactions between both parts [19]. Hydrofluoric acid (HF) etching is one of the most prevalent ways to efficiently bond resin to the surface of glass ceramics [16,19-34]. Cementation of glassy matrix ceramics following HF etching and silanization has been recommended in several studies $[17,19,27]$. By selectively dissolving the glassy ceramic matrix to create a rough surface, HF treatment improves the topography to favor micro-mechanical retention [11]. The bond affinity between fluoride and silicon is more significant than that between silicon and oxygen, explaining the mechanism. The acid selectively dissolves the glassy matrix of the lithium disilicate surface, exposing the crystalline structure responsible for resin cement micromechanical retention [11].

Nowadays, the laser technique is becoming more popular in the dentistry field. The Er:YAG laser wavelength is $2940 \mathrm{~nm}$, which corresponds to the maximum of water absorption at the invisible spectrum [18,29]. Heat treatment may accelerate the silane, resulting in a long-lasting bond that strengthens the composite-ceramic link [3,5,13,19,27-35]. Water, alcohol, and additional particles are removed from the ceramic surface during heat treatment; the removal of water accelerates the completion of the silane/silica surface condensation reaction and increases the creation of covalent silane/silica bonds. Evaporation of chemicals that would ordinarily hydrogen bond to the silica surface, such as alcohol, increases the number of bond sites available for interaction with silane [32,33]. Some methods have been described for the heat treatment, and the most common ones include drying with warm air $[3,32,33]$, rinsing with hot water [13,31], using a preheated furnace or hot air oven $[5,19,32]$, and a combination of these methods [15,33].

After the primer for adhesion was introduced, the conventional shear or tensile bond tests increased [34,35]. With this procedure, the measured pressures are around 18-20 MPa [34,35]. It was challenging to identify bond strength values that differed significantly. Additionally, failures with lower bond strength (9 MPa) were common $[34,35]$. A novel tensile bond test with a low surface area indicated more adhesive failure at the bonded interface or higher bond strength than conventional bond tests with larger surface areas, which occasionally indicated cohesive failure within dentin at less than $5 \mathrm{MPa}[34,35]$. The $\mu$ TBS test is now widely accepted as a versatile and reliable method of determining bond strength. Morphological and spectroscopic investigations demonstrated a greater discriminative capacity than the conventional macro-shear test in improving resin/dentin adhesion [36].

This study was conducted to compare the impact of different surface treatments and two methods of silan heat treatments (laser and furnace) on the bond strength between composite resin and lithium disilicate. According to the null hypothesis, silane heat treatment by Er:YAG laser could not improve the bond strengths enough to compare differing surface treatments between composite resin and lithium disilicate.

\section{Materials and Experiments}

The materials used in this study are listed in Table 1. 
Table 1. Materials used in the study.

\begin{tabular}{|c|c|c|}
\hline Material & Composition & Manufacturer \\
\hline IPS e. max Press & Lithium disilicate glass-ceramic & $\begin{array}{l}\text { Ivoclar Vivadent, } \\
\text { Schaan, Liechtenstein }\end{array}$ \\
\hline Tetric N-Ceram & dimethacrylates (19-20 wt \%) & $\begin{array}{l}\text { Ivoclar Vivadent, } \\
\text { Schaan, Liechtenstein }\end{array}$ \\
\hline Silane coupling agent & 3-glycidoxypropyltrimethoxysilane & $\begin{array}{l}\text { Ivoclar Vivadent, } \\
\text { Schaan, Liechtenstein }\end{array}$ \\
\hline CoJet-System & $\begin{array}{l}\text { Sand }\left(\text { CoJet }^{\circledR \circledR} \text { Sand): Silicatized sand }\right. \\
\text { (particle size } 30 \mu \mathrm{m}) ; \text { Silane (ESPE } \\
\left.\text { Sil }{ }^{\circledR \circledR}\right) \text { : Silane with an attached } \\
\text { methacrylic group; and Ethanol } \\
\left.\text { Bonding agent (Visio-Bond }{ }^{\circledR \circledR}\right) \text { : } \\
\text { Bisacrylate, Aminodiolmethacrylate, } \\
\text { Camphor quinine, } \\
\text { Benzyldimethylketale, and Stabilizers }\end{array}$ & 3M ESPE, Seefeld, Germany \\
\hline Korox 50 & $\mathrm{Al}_{2} \mathrm{O}_{3}$ particles & Bego, Bremen, Germany \\
\hline Porcelain Etch & Hydrofluoric acid & $\begin{array}{l}\text { Ultraden Products Inc. South } \\
\text { Jordan, UT, USA }\end{array}$ \\
\hline Variolink-N & $\begin{array}{l}\text { BISGMA, Barium, Glass filler, } \\
\text { Di-methacrylates, Pigments, } \\
\text { Initiators, Stabilizers, Silica }\end{array}$ & $\begin{array}{l}\text { Ivoclar Vivadent, } \\
\text { Schaan, Liechtenstein }\end{array}$ \\
\hline
\end{tabular}

Seventy square-shaped lithium disilicate (IPS e. max Press; Ivoclar Vivadent, Schaan, Liechtenstein) ingots $(13 \mathrm{~mm} \times 13 \mathrm{~mm} \times 13 \mathrm{~mm}$ ) were made using the lost-wax method, followed by ceramic ingots injected under high pressure at $925{ }^{\circ} \mathrm{C}$ for 20 min under a pressure of 4.5 bar in a furnace (Programat EP500, Ivoclar Vivadent, Schaan, Liechtenstein) [37] according to the manufacturer's instructions. All specimens were mechanically polished with silicon carbide abrasives of 600,800 , and 1000 grit. To make a duplicate mold for the polymerization of composite blocks, ceramic blocks were inserted in polyvinyl siloxane impression material (Elite HD+; Zhermack, Badia Polesine, Italy). Composite resin (Tetric N-Ceram; Ivoclar Vivadent) layers up to $1.5 \mathrm{~mm}$ thick were placed into copy molds, then polymerized for $20 \mathrm{~s}$ with a light-emitting diode (LED) (Hilux LED MAX 1055; Benlioglu dental, Çankaya/Ankara, Turkey), yielding 70 composite resin blocks with the exact dimensions of the ceramic blocks.

All specimens were divided into seven groups:

- S group (silane): A silane coupling agent (Monobond S, Ivoclar Vivadent, Schaan, Liechtenstein) was applied to the surface specimens for $1 \mathrm{~min}$ and then air-dried for $30 \mathrm{~s}$.

- SC group: Air abrasion was applied by $30 \mathrm{~m}$ aluminum oxide $\left(\mathrm{Al}_{2} \mathrm{O}_{3}\right)$ particles modified with silica (Cojet Sand; Seefeld, Germany) at a pressure of 2.3 bar from a distance of $10 \mathrm{~mm}$ for $15 \mathrm{~s}$ (tribochemical silica coating). Then silane was applied.

- $\quad \operatorname{ALS}\left(\mathrm{AL} \pm\right.$ silane) group: Sandblasting was performed with $50 \mathrm{~m} \mathrm{Al}_{2} \mathrm{O}_{3}$ particles (Korox 50; Bego Bremen, Germany) at a pressure of $0.3 \mathrm{MPa}$ from a distance of $10 \mathrm{~mm}$ for $10 \mathrm{~s}$ [38]. Then silane was applied.

- $\quad$ SHT1 group (laser \pm silane): Specimens were irradiated for $30 \mathrm{~s}$ with an Er:YAG laser using a non-contact head. The laser had a frequency of $20 \mathrm{~Hz}$, a long pulse of $5 \mathrm{~W}$, and a power of $250 \mathrm{~mJ}$.

- $\quad$ SHT2 group (silane \pm heat treatment): Silane was applied on the surface according to the same procedure and then heat treatment was performed in the furnace $\left(100^{\circ} \mathrm{C}\right.$, $1 \mathrm{~min})$. 
- HF group: The surface of the specimens was etched for 20s with 9.5 percent HF gel (Porcelain Etch; Ultradent Products Inc, South Jordan, UT, USA), washed for $1 \mathrm{~min}$, and air-dried for $1 \mathrm{~min}$.

- $\quad$ HFS group (HF \pm silane): The acid-etching methodology was used. The technique was also followed by silanization.

The ceramic specimens were glued to composite resin (Tetric N-Ceram; Ivoclar Vivadent, Schaan, Liechtenstein) under a $500 \mathrm{~g}$ load after surface treatment. For $24 \mathrm{~h}$, bonded specimens (ceramic-composite) were kept in dark containers filled with distilled water at $37^{\circ} \mathrm{C}$. All specimens were aged (thermal cycling 5000 cycles, $5-55{ }^{\circ} \mathrm{C}$, dwell time: $30 \mathrm{~s}$ ) before the microtensile bond strength test ( $\mu \mathrm{TBS}$ ) (Dentist Solubris Technica, Istanbul, Türkiye) [30].

The specimens were embedded in acrylic resin (Paladent; Heraeus Kulzer, Hanau, Germany and longitudinally sectioned at $1.3 \mathrm{~mm}$ intervals in both $\mathrm{X}$ and $\mathrm{Y}$ directions, perpendicular to the resin/ceramic interface, with a precision saw (Isomet 1000; Buehler, Illinois, ABD). Under a stereomicroscope (Leica S4 E; Leica Microsystems, Heerbrugg, Switzerland), the ceramic-composite microbars $(661 \mathrm{~mm})$ were examined and evaluated for crack formation.

\subsection{Microtensile Bond Strength Test ( $\mu$ TBS)}

Every specimen was bonded to a microtensile testing machine (Micro Tensile Tester; BISCO Dental Products, Richmond, VA, USA) with cyanoacrylate (Pattex; Henkel, Germany) and exposed to tensile force at a crosshead speed of $1.0 \mathrm{~mm} / \mathrm{min}$. $\mu$ TBS was calculated using the load at fracture $(\mathrm{P})$ and is expressed in $\mathrm{MPa}$ using the $\mathrm{P} / \mathrm{A}$ formula $\left(\mathrm{N} / \mathrm{mm}^{2}\right)$.

\subsection{Failure Mode}

A stereomicroscope (Kaps ENT SOM Microscope, Asslar, Germany) was used to examine the debonded surfaces of the specimens at a magnification of $20 \times$ to determine the forms of failure (adhesive, cohesive, or mixed). In this study, we evaluated five types of adhesive failure mode [39].

\subsection{Scanning Electron Microscopi (SEM)}

A scanning electron microscope (SEM) (JSM-7001F; JEOL, Musashino, Akishima, Japan) was used to analyze one tested specimen from every group at $1000 \times$ magnification to assess surface characteristics of the performed treatment processes (Figure 1).
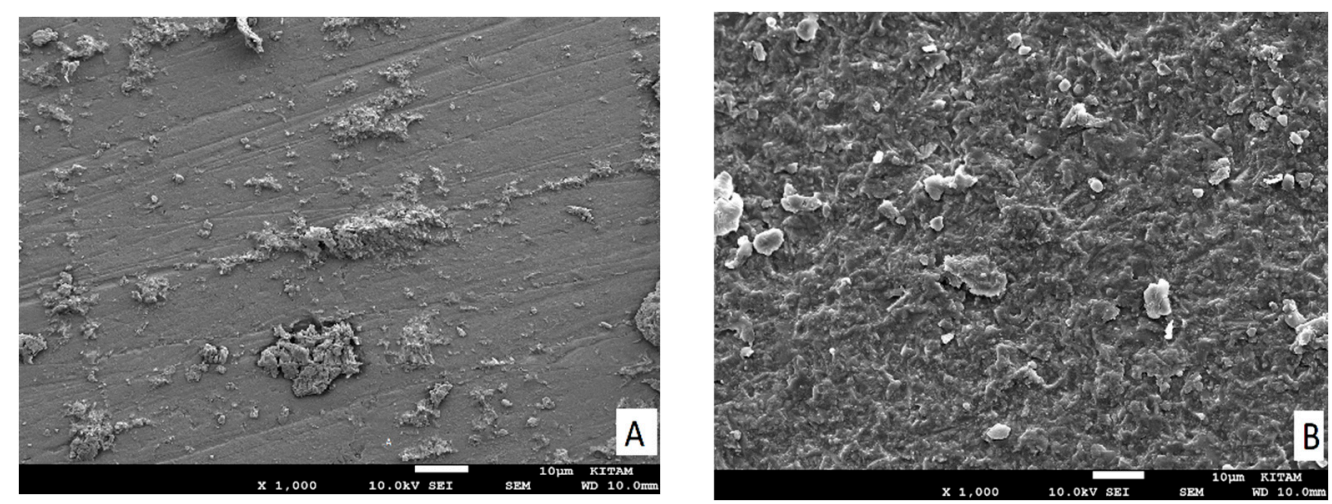

Figure 1. Cont. 

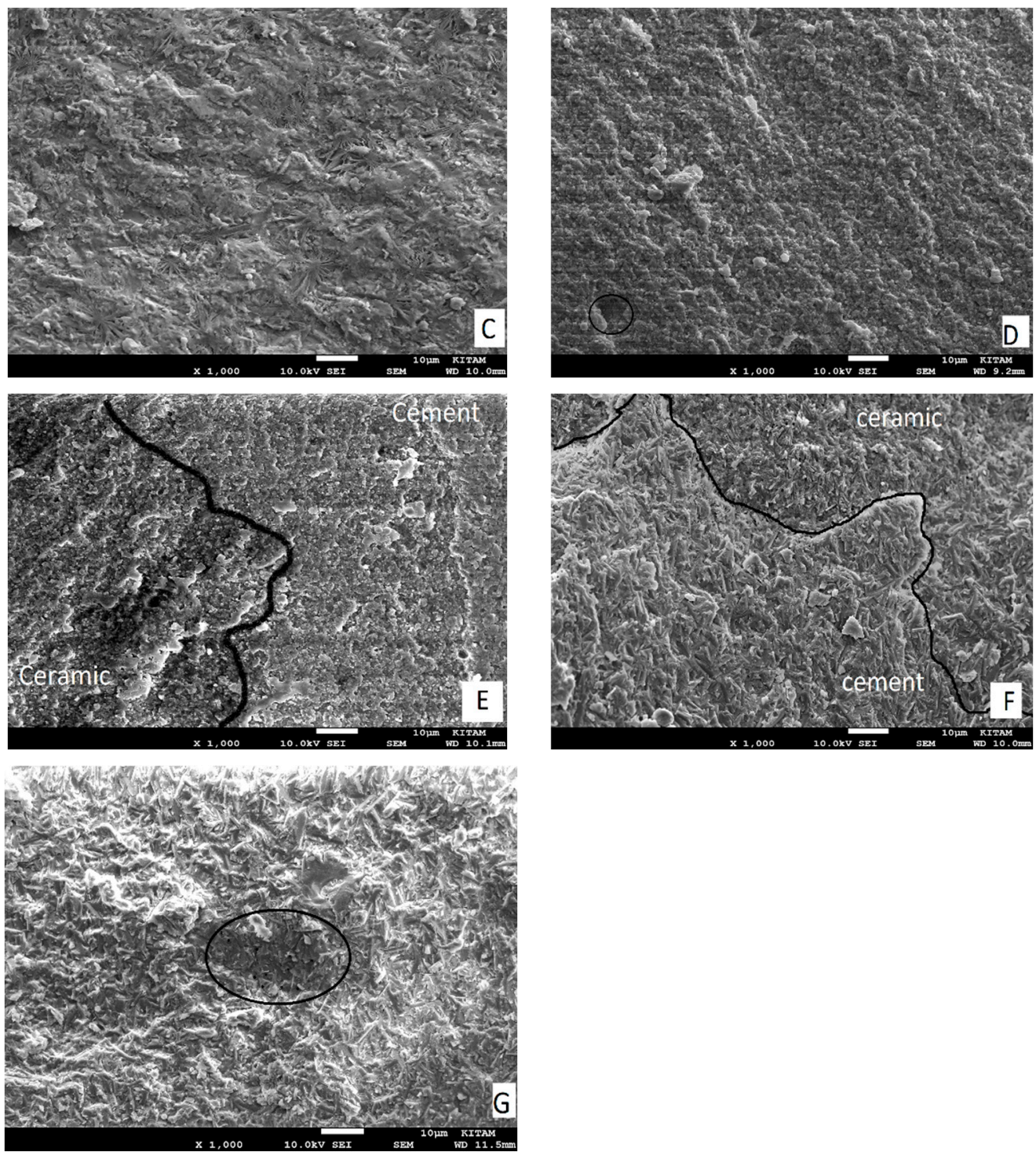

Figure 1. SEM micrographs of failure modes and the ceramic surface after treatment in a representative specimen: (A) Group S: adhesive failure (mode 1), where no trace of other substrate was found on the surface. (B) Group SC: adhesive failure (mode 4), where failure starts at the ceramic-adhesive interface as a corner flaw (lower left) and propagates through the adhesive resin. (C) Group ALS: adhesive failure (mode 5), where trace or other substrate was found on the surface. (D) Group SHT1) adhesive failure (Mode 2), the semicircular flaw is the crack origin; the adhesive resin is in the middle of the fracture surface. (E) Group SHT2: mixed failure mode, in a representative sample; lithium disilicate crystals are scarcely evident on the uncovered ceramic surface. (F) Group HF: mixed failure mode in a representative sample; the ceramic surface (black area) is partly covered with cement (white area), ceramic crystals are visible following the removal of the glassy phase. (G) Group SHF: adhesive failure (Mode 3), where the internal defect is the origin of the crack (black circle), the cement in the center of the fracture surface representing what qualifies as a failure.

\subsection{Statistical Analysis}

To evaluate significant changes across surface treatments, one-way ANOVA (IBM SPSS Statistics v21.0; IBM Corp, New York, Acmon, USA) and Tamhane T2 tests were performed. 0.05 was used as the significant level. 


\section{Results}

\subsection{Microtensile Bond Strength Test ( $\mu$ TBS)}

A one-way ANOVA analysis revealed statistically significant differences between the different surface treatment groups. $(\mathrm{df}=6 ; \mathrm{F}=50.75 ; p<0.001)$. The study groups ${ }^{\prime}$ mean, minimum, and maximum TBS values and standard deviations are shown in the list in Table 2. Group SHT1 had the highest mean bond strength (27.84 MPa), which was substantially different $(p<0.001)$ from that of the other groups. Group ALS had the lowest mean bond strength $(15.62 \mathrm{MPa})$, which was likewise substantially different $(p<0.001)$ from that of the other groups, excluding the $S$ group. No statistically significant difference $(p=1)$ was discovered between groups SHT2 and HFS, or between groups S and SC, according to the Tamhane $\mathrm{T} 2$ test results (Table 3).

Table 2. Mean, minimum, maximum bond strength values and standard deviations of groups.

\begin{tabular}{cccc}
\hline Group & Mean \pm SD & Min & Max \\
\hline S & $20.12^{\mathrm{a}} \pm 1.71$ & 12 & 29 \\
SC & $20.78^{\mathrm{a}} \pm 1.85$ & 14 & 28 \\
ALS & $15.62^{\mathrm{b}} \pm 1.79$ & 10 & 19 \\
SHT1 & $27.46^{\mathrm{c}} \pm 0.97$ & 16 & 36 \\
SHT2 & $26.74^{\mathrm{c}} \pm 0.82$ & 16 & 35 \\
HF & $25.77^{\mathrm{c}} \pm 1.21$ & 20 & 43 \\
HFS & $26.06^{\mathrm{d}} \pm 1.41$ & 31 & \\
\hline
\end{tabular}

No significant differences were found between groups with the same superscript letter.

Table 3. Tamhane $\mathrm{T} 2$ test results.

\begin{tabular}{ccccccc}
\hline Group & CS & ALS & SHT1 & SHT2 & HF & HFS \\
\hline S & $p=1$ & $p=0.001$ & $p<0.001$ & $p<0.001$ & $p=0.001$ & $p<0.001$ \\
SC & & $p<0.001$ & $p<0.001$ & $p<0.001$ & $p=0.008$ & $p<0.001$ \\
ALS & & & $p<0.001$ & $p<0.001$ & $p<0.001$ & $p<0.001$ \\
SHT1 & & & & $p<0.001$ & $p<0.001$ & $p<0.001$ \\
SHT2 & & & & $p<0.001$ & $p=1$ \\
HF & & & & & & $p<0.001$ \\
\hline
\end{tabular}

\subsection{Failure Mode}

Both mixed and adhesive-mode failures were discovered when the specimens were debonded. This study also observed five types of adhesive failure mode: 1: adhesive failure separation at the ceramic-cement interface (mode 1); 2 : failure originating at the ceramic-cement interface, progressing into the adhesive resin, and returning to the interface (mode 2); 3: failure starting from an internal flaw (mode 3); 4: failure originating at the ceramic-cement interface and spreading to the adhesive resin (mode 4); 5 : failure starting at the ceramic-cement interface and spreading to the adhesive resin to reach the resin composite-cement interface (mode 5) [39]. There was no evidence of cohesive failure in any of the specimens used in this study (Table 4; Figure 1).

\subsection{Scanning Electron Microscopi (SEM)}

From SEM analysis of the surface ceramic (Figure $1 \mathrm{~A}-\mathrm{G}$ ), we found that the pattern was mixed with failures where the ceramic surface was partially exposed and partially covered in cement. The resin cement layer is shown in white in the micrographs, while the lithium disilicate surface area is shown in the dark. The ALS group's exposed ceramic surface area was found to be smaller in the SEM analysis (Figure 1C) and had fewer irregularities than those in the HFS (Figure 1E), SHT2 (Figure 1D), and HF (Figure 1F) groups. The silane heat treatment by Er:YAG laser resulted in additional deterioration and surface imperfections in the ceramic (Figure 1D). 
Table 4. Types of bond failures.

\begin{tabular}{cccc}
\hline Group & Adhesive $^{*}$ & Cohesive $^{*}$ & Mixed $^{*}$ \\
\hline S & $8(80)$ & - & $2(20)$ \\
\hline SC & $7(70)$ & - & $3(30)$ \\
\hline ALS & $9(90)$ & - & $1(10)$ \\
\hline SHT1 & $5(50)$ & - & $5(50)$ \\
\hline SHT2 & $6(60)$ & - & $4(40)$ \\
\hline HF & $8(80)$ & - & $2(20)$ \\
\hline HFS & $4(40)$ & - & $6(60)$ \\
\hline${ }^{*} \mathrm{n}(\%)$. & $47(67.1)$ & &
\end{tabular}

\section{Discussion}

In this study, we investigated the effects of several surface treatments and two silan heat treatment procedures on the binding strength between composite resin and lithium disilicate. The results reject the null hypothesis because silane heat treatment by Er:YAG laser improved the bond strengths between composite resin and lithium disilicate when compared to different surface treatments.Ceramic surface treatment is an important step to improve the strong bond between the ceramic and composite resin [18].

Several studies have found that typical HF treatment followed by silanization considerably boosted the resin bond strength of lithium disilicate ceramics $[15,19,24,26]$. The effects of HF acid on the morphology of glass ceramics' surfaces following silane coupling have been thoroughly researched. The chemical reaction between hydrofluoric acid and silica represents the glass phase in lithium-disilicate-based glass-ceramic materials made from hexafluorosilicates. These silicates are removed under running water after HF etching, resulting in micropores that create an asymmetrical roughness on the surface $[16,26,40,41]$. Furthermore, the impact of silanization on the ceramic surface is indicated by the results of this study. Compared to those ceramics treated with HF and then silanized, specimens treated with HF alone had lower mean TBS values than HFS $(p<0.001)$. By establishing a siloxane link between the ceramic's inorganic phase and the resin's cement organic phase, silane agents operate as bridges that boost the surface energy and wettability of the ceramic surface, promoting the resin-ceramic bond strength [19,28,33,34].

Kim et al. [22] investigated the effects of surface treatment on the resin bond strength of various ceramic systems, and revealed that tribochemical coating significantly increased the bond strength of zirconia and alumina-based ceramics. In contrast, a combination of APA and HF etching significantly increased the bond strength of lithium-disilicate-based and feldspathic ceramics.

Bottino et al. [23] studied the effect of surface treatments on the surface morphology of high-alumina and glass-matrix ceramics and concluded that silica coating had no discernible effect on the surface morphology of either ceramic system. Tribochemical silica coating and APA techniques could not be used as alternatives to HF treatment followed by silanization.

Micromechanical retention is commonly achieved via airborne particle abrasion (APA) $[17,26]$. The lowest mean $\mu$ TBS value was found in air-abraded and then silanized (ALS) groups in this investigation, which is similar to the findings of some studies [3,20,21]. Silanization alone versus tribochemical silica coating followed by silanization did not significantly differ the results $(p=1)$ according to the findings of this study.

This study aimed to examine how heat treatment affects the resin bond strength of silanized lithium-disilicate-based ceramics. Heat treatment has been shown to significantly increase resin-ceramic bond strength in certain studies [5,13,30,32], whereas it did not in others $[3,19,32,33]$. In this study, heat treatment with an Er:YAG laser considerably boosted the resin bond strength of silanized lithium disilicate ceramics compared to the other 
groups. Similar to the present results, a previous study reported that using the Er:YAG laser irradiation before silane treatment can improve a resin's bond strength to the ceramic surface [18].

Water, alcohol, and other by-products are eliminated from the ceramic surface following silanization before heat treatment, improving the chemical activity of silane coupling agents, and speeding up the condensation process between silicate and silane, boosting resin-ceramic bond strength $[19,31,33]$. The mean $\mu$ TBS values of heat-treated, silanized specimens were similar to those for the HFS treatment $(p<0.001)$, which is considerably higher than the other treatment, except for heat treatment with an Er:YAG.

The study's limitation is that the laboratory study design could not wholly replicate clinical settings. Different outcomes could be obtained at different temperatures, and the varying laser settings could be utilized to affect the alterations in the superficial layers of ceramic surfaces. Furthermore, no additional surface treatment approach that could cause micromechanical roughening and enhance surface energy was used in conjunction with the heat treatment procedures. Perhaps particle abrasions, such as tribochemical silica coating, and subsequent heat treatment after silanization will produce superior bond strength outcomes. To investigate the long-term clinical consequences of post-silanization heat therapy, more in vivo research is needed.

\section{Conclusions}

The mean $\mu$ TBS value after silane heat treatment by Er:YAG laser increased. The silane heat treatment was similar to HF etching and silane treatment.

The resin-ceramic bond strength significantly improved after heat treatment and heat treatment can increase the strength of the bond between feldspathic porcelain and composite resin.

Author Contributions: Conceptualization: R.S., G.E.-K. and M.Ö.; investigation: G.E.-K. and M.F.K.; methodology: R.S. and G.E.-K.; supervision: R.S. and G.E.-K.; writing-original draft: R.S. and G.E.-K.; writing-review and editing: R.S., G.E.-K. and M.Ö. All authors have read and agreed to the published version of the manuscript.

Funding: This research received no external funding.

Institutional Review Board Statement: Not applicable.

Informed Consent Statement: Not applicable.

Data Availability Statement: The data presented in this study are available upon request from the corresponding author.

Conflicts of Interest: The authors declare no conflict of interest.

\section{References}

1. Tian, T.; Tsoi, J.K.H.; Matinlinna, J.P.; Burrow, M.F. Aspects of bonding between resin luting cements and glass-ceramic materials. Dent. Mater. 2014, 30, 147-162. [CrossRef]

2. Marocho, S.M.S.; Özcan, M.; Amaral, R.; Bottino, M.A.; Valandro, L.F. Effect of resin cement type on the microtensile bond strength to lithium disilicate ceramic and dentin using different test assemblies. J. Adhes. Dent. 2013, 15, 361-368.

3. Colares, R.C.R.; Neri, J.R.; de Souza, A.M.B.; Pontes, K.M.; Mendonça, J.S.; Santiago, S.L. Effect of surface preparements on the microtensile bond strength of lithium-disilicate ceramic repaired with composite resin. Braz. Dent. J. 2013, 24, 349-352. [CrossRef]

4. Sundfeld, D.; Correr-Sobrinho, L.; Pini, N.I.P.; Costa, A.R.; Sundfeld, R.H.; Pfeifer, C.S.; Martins, L.R.M. Heat treatment-improved bond strength of resin cement to lithium disilicate glass-ceramic. Ceram. Int. 2016, 42, 10071-10078. [CrossRef]

5. Abduljabbar, T.; AlQahtani, M.A.; Jeaidi, Z.A.; Vohra, F. Influence of silane and heated silane on the bond strength of lithium disilicate ceramics-an in vitro study. Pak. J. Med. Sci. 2016, 32, 550-554. [CrossRef]

6. Araujo, N.S.; Moda, M.D.; Silva, E.A.; Zavanelli, A.C.; Mazaro, J.V.Q.; Pellizzer, E.P. Survival of all-ceramic restorations after a minimum follow-up of five years: A systematic review. Quintessence Int. 2016, 47, 395-405.

7. Gracis, S.; Thompson, V.P.; Ferencz, J.L.; Silva, N.R.F.A.; Bonfante, E.A. A new classification system for all-ceramic and ceramic-like restorative materials. Int. J. Prosthodont. 2015, 28, 227-235. [CrossRef] 
8. Cappare, P.; Ferrini, F.; Mariani, G.; Nagni, M.; Cattoni, F. Implant rehabilitation of edentulous jaws with predominantly monolithic zirconia compared to metal-acrylic prostheses: A 2-year retrospective clinical study. J. Biol. Regul. Homeost. Agents 2021, 35, 99-112.

9. Ritter, R.G. Multifunctional uses of a novel ceramic-lithium disilicate. J. Esthet. Restor. Dent. 2010, 22, 332-341. [CrossRef]

10. Huang, S.; Li, Y.; Wei, S.; Huang, Z.; Gao, W.; Cao, P. A novel high-strength lithium disilicate glass-ceramic featuring a highly intertwined microstructure. J. Eur. Ceram. Soc. 2017, 37, 1083-1094. [CrossRef]

11. Aboushelib, M.N.; Sleem, D. Microtensile bond strength of lithium disilicate ceramics to resin adhesives. J. Adhes. Dent. 2014, 16, 547-552.

12. Campaner, L.M.; Silveira, M.P.M.; de Andrade, G.S.; Borges, A.L.S.; Bottino, M.A.; Dal Piva, A.M.O.; Giudice, R.L.; Ausiello, P.; Tribst, J.P.M. Influence of polymeric restorative materials on the stress distribution in posterior fixed partial dentures: 3D finite element analysis. Polymers 2021, 13, 758. [CrossRef] [PubMed]

13. Tetè, G.; Sacchi, L.; Camerano, C.; Nagni, M.; Capelli, O.; Vercellin, S.C.; La Rocca, G.; Polizzi, E. Management of the delicate phase of the temporary crown: An in vitro study. J. Biol. Regul. Homeost. Agents 2020, 34, 69-80. [PubMed]

14. Conrad, H.J.; Seong, W.J.; Pesun, I.J. Current ceramic materials and systems with clinical recommendations: A systematic review. J. Prosthet. Dent. 2007, 98, 389-404. [CrossRef]

15. Ciancaglini, R.; Gherlone, E.F.; Redaelli, S.; Radaelli, G. The distribution of occlusal contacts in the intercuspal position and temporomandibular disorder. J. Oral Rehabil. 2002, 29, 1082-1090. [CrossRef]

16. Pollington, S.; Fabianelli, A.; van Noort, R. Microtensile bond strength of a resin cement to a novel fluorcanasite glass-ceramic following different surface treatments. Dent. Mater. 2010, 26, 864-872. [CrossRef]

17. Lung, C.Y.K.; Matinlinna, J.P. Aspects of silane coupling agents and surface conditioning in dentistry: An overview. Dent. Mater. 2012, 28, 467-477. [CrossRef] [PubMed]

18. Hakimaneh, M.S.; Sayed-Shojaedin, S.; Ghavami-Lahiji, M.; Chokr, A.; Moraditalab, A. Effect of Silane Heat Treatment by Laser on the Bond Strength of a Repair Composite to Feldspathic Porcelain. J. Prosthodont. 2020, 29, 49-55. [CrossRef] [PubMed]

19. Yavuz, T.; Eraslan, O. The effect of silane applied to glass-ceramics on surface structure and bonding strength at different temperatures. J. Adv. Prosthodont. 2016, 8, 75-84. [CrossRef] [PubMed]

20. Guarda, G.B.; Correr, A.B.; Gonçalves, L.S.; Costa, A.R.; Borges, G.A.; Sinhoreti, M.A.C.; Correr-Sobrinho, L. Effects of surface treatments, thermocycling, and cyclic loading on the bond strength of a resin cement bonded to a lithium disilicate glass-ceramic. Oper. Dent. 2013, 38, 208-217. [CrossRef]

21. Spohr, A.M.; Sobrinho, L.C.; Consani, S.; Sinhoretti, M.A.C.; Knowles, J.C. Influence of surface conditioning and silane agent on the bond of resin to IPS Empress 2 ceramic. Int. J. Prosthodont. 2003, 16, 277-282. [PubMed]

22. Kim, B.K.; Bae, H.E.K.; Shim, J.S.; Lee, K.W. The influence of ceramic surface treatments on the tensile bond strength of composite resin to all-ceramic coping materials. J. Prosthet. Dent. 2005, 94, 357-362. [CrossRef]

23. Bottino, M.C.; Özcan, M.; Coelho, P.G.; Valandro, L.F.; Bresciani, J.C.; Bresciani, A.H.A. Micro-morphological changes prior to adhesive bonding: High-alumina and glassy-matrix ceramics. Braz. Oral Res. 2008, 22, 158-163. [CrossRef] [PubMed]

24. Yavuz, T. Özyılmaz, Ö.Y.; Dilber, E.; Tobi, E.S.; Kiliç, H.Ş. Effect of different surface treatments on porcelain-resin bond strength. J. Prosthodont. 2017, 26, 446-454. [CrossRef] [PubMed]

25. Yavuz, T.; Dilber, E.; Kara, H.B.; Tuncdemir, A.R.; Ozturk, A.N. Effects of different surface treatments on shear bond strength in two different ceramic systems. Lasers Med. Sci. 2013, 28, 1233-1239. [CrossRef]

26. Özcan, M.; Vallittu, P.K. Effect of surface conditioning methods on the bond strength of luting cement to ceramics. Dent. Mater. 2003, 19, 725-731. [CrossRef]

27. Özcan, M.; Allahbeickaraghi, A.; Dündar, M. Possible hazardous effects of hydrofluoric acid and recommendations for treatment approach: A review. Clin. Oral Investig. 2012, 16, 15-23. [CrossRef]

28. Helbling, F.; Özcan, M. Adhesion of resin cement to contemporary hybrid ceramic and polymeric CAD/CAM materials: Effect of conditioning methods and aging. J. Adhes. Sci. Technol. 2019, 33, 886-902. [CrossRef]

29. de Paula Eduardo, P.; Bello-Silva, M.S.; Moretto, S.G.; Cesar, P.F.; de Freitas, P.M. Microtensile bond strength of composite resin to glass-infiltrated alumina composite conditioned with Er,Cr:YSGG laser. Lasers Med. Sci. 2012, 27, 7-14. [CrossRef]

30. Corazza, P.H.; Cavalcanti, S.C.M.; Queiroz, J.R.C.; Bottino, M.A.; Valandro, L.F. Effect of post silanization heat treatments of silanized feldspathic ceramic on adhesion to resin cement. J. Adhes. Dent. 2013, 15, 473-479.

31. Fabianelli, A.; Pollington, S.; Papacchini, F.; Goracci, C.; Cantoro, A.; Ferrari, M.; van Noort, R. The effect of different surface treatments on bond strength between leucite reinforced feldspathic ceramic and composite resin. J. Dent. 2010, 38, 39-43. [CrossRef] [PubMed]

32. de Figueiredo, V.M.G.; Corazza, P.H.; Lepesqueur, L.S.S.; Miranda, G.M.; Pagani, C.; de Melo, R.M.; Valandro, L.F. Heat treatment of silanized feldspathic ceramics: Effect on the bond strength to resin after thermocycling. Int. J. Adhes. Adhes. 2015, 63, 96-101. [CrossRef]

33. de Carvalho, R.F.; Martins, M.E.M.N.; de Queiroz, J.R.C.; Leite, F.P.P.; Özcan, M. Influence of silane heat treatment on bond strength of resin cement to a feldspathic ceramic. Dent. Mater. 2011, 30, 392-397. [CrossRef]

34. Monticelli, F.; Toledano, M.; Osorio, R.; Ferrari, M. Effect of temperature on the silane coupling agents when bonding core resin to quartz fiber posts. Dent. Mater. 2006, 22, 1024-1028. [CrossRef] [PubMed] 
35. Armstrong, S.; Breschi, L.; Özcan, M.; Pfefferkorn, F.; Ferrari, M.; Van Meerbeek, B. Academy of Dental Materials guidance on in vitro testing of dental composite bonding effectiveness to dentin/enamel using micro-tensile bond strength ( $\mu$ TBS) approach. Dent. Mater. 2017, 33, 133-143. [CrossRef]

36. Sano, H.; Chowdhury, A.F.M.A.; Saikaew, P.; Matsumoto, M.; Hoshika, S.; Yamauti, M. The microtensile bond strength test: Its historical background and application to bond testing. Jpn. Dent. Sci. Rev. 2020, 56, 24-31. [CrossRef]

37. Nagarkar, S.; Theis-Mahon, N.; Perdigão, J. Universal dental adhesives: Current status, laboratory testing, and clinical performance. J. Biomed. Mater. Res. B Appl. Biomater. 2018, 107, 2121-2131. [CrossRef] [PubMed]

38. Sasany, R.; Sarac, D.; Kunt, G.E. Effect of various veneering techniques on bond strength and colour stability of zirconia/veneering ceramic after hydrothermal aging. J. Evolution. Med. Dent. Sci. 2021, 10, 3474-3479. [CrossRef]

39. Sasany, R.; Saraç, D.; Özcan, M. Effect of different liner techniques and argon plasma treatment of zirconia base on the adhesion and colour change of veneering ceramic. J. Adhes. Sci. Technol. 2021, 35, 1981-1994. [CrossRef]

40. Della Bona, A.; Anusavice, K.J.; Mecholsky, J.J., Jr. Failure analysis of resin composite bonded to ceramic. Dent. Mater. 2003, 19, 693-699. [CrossRef]

41. Ramakrishnaiah, R.; Alkheraif, A.A.; Divakar, D.D.; Matinlinna, J.P.; Vallittu, P.K. The Effect of Hydrofluoric Acid Etching Duration on the Surface Micromorphology, Roughness, and Wettability of Dental Ceramics. Int. J. Mol. Sci. 2016, 17, 822. [CrossRef] [PubMed] 